\title{
Development of New Technologies for Stem Cell Research
}

\author{
Xibo Ma, ${ }^{1}$ Qian Zhang, ${ }^{2}$ Xin Yang, ${ }^{1}$ and Jie Tian ${ }^{1,2}$ \\ ${ }^{1}$ Intelligent Medical Research Center, State Key Laboratory of Management and Control for Complex Systems, \\ Institute of Automation, Chinese Academy of Sciences, Beijing 100190, China \\ ${ }^{2}$ School of Life Sciences and Technology, Xidian University, Shaanxi, Xi'an 710071, China \\ Correspondence should be addressed to Jie Tian, tian@ieee.org
}

Received 16 June 2012; Accepted 27 September 2012

Academic Editor: Ken-ichi Isobe

Copyright () 2012 Xibo Ma et al. This is an open access article distributed under the Creative Commons Attribution License, which permits unrestricted use, distribution, and reproduction in any medium, provided the original work is properly cited.

Since the 1960s, the stem cells have been extensively studied including embryonic stem cells, neural stem cells, bone marrow hematopoietic stem cells, and mesenchymal stem cells. In the recent years, several stem cells have been initially used in the treatment of diseases, such as in bone marrow transplant. At the same time, isolation and culture experimental technologies for stem cell research have been widely developed in recent years. In addition, molecular imaging technologies including optical molecular imaging, positron emission tomography, single-photon emission computed tomography, and computed tomography have been developed rapidly in recent the 10 years and have also been used in the research on disease mechanism and evaluation of treatment of disease related with stem cells. This paper will focus on recent typical isolation, culture, and observation techniques of stem cells followed by a concise introduction. Finally, the current challenges and the future applications of the new technologies in stem cells are given according to the understanding of the authors, and the paper is then concluded.

\section{Introduction}

Stem cells are a kind of cells that have the ability to perpetuate themselves through self-renewal and to generate functional mature cells of a particular tissue through differentiation $[1,2]$. So far, stem cells do not have a clear definition which can be used to distinguish them from other cells. However, most of researchers believe that, in general sense, stem cells need to meet the following criteria. First of all, stem cells are capable of continuous, repeated self-renewal divisions in order to maintain the stem cell population. Secondly, a single stem cell can differentiate into a variety of mature cells. Thirdly, stem cells can rebuild the organization when they are transplanted into its source damaged organization. Lastly, even if the tissue does not suffer, stem cells can differentiate into mature cells of the tissue.

In recent years, tumor stem cells increasingly attracted much more attention of researchers. Many researchers found that malignant tumor growth, recurrence, and metastasis were similar to the corresponding characteristics of stem cells [1-3]. With the deepening of research on stem cell and tumor biology, tumor stem cells are initially found in acute myeloid leukemia (AML) [4-8]. Park and his partners had proved that only a small part of the cell subsets of leukemia and multiple myeloma cells have unlimited proliferative capacity, accounting for $1 \%-4 \%$ and $0.001 \%-1 \%$ of the total number of tumor cells, respectively [4]. Salmon's group had successfully identified and separated the tumor stem cells with CD34 (+)/CD $38(-)$ phenotype from the human acute myeloid leukemia tumor cells for the first time [5]. Afterwards, Morrison's and Licht's groups had done some researches on the targets of the AML and this work would surely promote the development of clinical treatment of AML [6-8].

For stem cell research, some technologies are frequently used including stem cell culture, separation, and identification techniques. At present, fluorescence activated cell sorting (FACS) and magnetic activated cell sorting (MACS) are the common separation methods for stem cells. Among them, FACS is the most widely used method. Researchers had obtained the cancer stem cells from breast cancer, brain gliomas, prostate cancer [9], gastric cancer [10], lung cancer [11], liver cancer [12], and pancreatic cancer [13, 14] using this method. In addition, some cell labeling technique had also been applied in stem cell research. Perrimon's group had labeled the cell using site-specific recombinant technique 
to randomly activate the lacZ gene in cell population [15]. Through labeling some specific gene, function of the stem cell could be detected and identified [16]. Lastly, with the advances in microscopy, confocal microscopy techniques have been developed and used to observe the stem cells and their surroundings.

In 1999, Weissleder and his partners proposed the concept of molecular imaging at Harvard University [17]. Through 10 years of development, this technology has been widely applied to many aspects of the life sciences. The goal of molecular imaging is to depict noninvasively in vivo cellular and molecular processes sensitively and specifically, such as monitoring multiple molecular events, cell trafficking and targeting [18-20]. In recent years, some new algorithms especially in optical molecular imaging area have been developed, such as multilevel adaptive finite element method [18], Bayesian approach [21], and graph cuts [22]. At the same time, with the advances of hardware and machine technique, some new molecular imaging systems had been developed, such as Spectrum CT of Cold Spring Biotech Corporation with three-dimensional imaging functional. In addition, Cerenkov luminescence imaging (CLI) using Cerenkov theory had been developed to capture the signals derived from ${ }^{18} \mathrm{~F}$-FDG probe. Compared to the traditional imaging method, all these imaging technologies had shown its advantage in tumor mechanism and antitumor evaluation research and had been initially applied in the stem cell research.

In this review paper, we will focus on the following three aspects. Firstly, we will introduce some new isolation and culture technology and review its application in stem cell research. Secondly, we will introduce several molecular imaging techniques and review some researchers' work on stem cells using these techniques. Finally, we will predict the future prospects to conclude the paper.

\section{New Isolation and Culture Technology and Its Application in Stem Cells Research}

Traditional culture methods typically involve reprogramming somatic cells to pluripotency by serial passage under adherent culture conditions on feeder cells or on extracellular matrix compounds [25]. The stem cells using these approaches likely to be contaminated by pathogens; these approaches are require separation of feeder cells from the cell type of interest which increase costs and are prone to differentiate variability. In recent years, many new isolation and culture technologies have been developed to obtain stem cells for their wide application prospects in disease mechanism and its treatment including suspension technology [23] and SB431542 inhibitor differentiation method [24].

2.1. Suspension Technology. Induced pluripotent stem cells (iPSCs) draw more and more attention because of their therapeutic advantages in enabling the generation of high-quality disease models, derivation of individual-specific iPSC lines, improving the predictability of drug action, and as a source of cells for regenerative medicine [23]. Zandstra's group had developed a way to obtain induced pluripotent stem cells in continuous adherence- and matrix-free suspension culture system, which has the potential to accelerate and standardize iPSCs research. The gene expression analysis showed high correlation between the two processes including reprogramming in suspension culture and that in routine adherent culture with regard to hallmark reprogramming genes.

2.2. SB431542 Inhibitor Differentiation Method. Mesenchymal stem cells are one kind of adult stem cells, which mainly derived from bone marrow stromal cells. Because of their ability to differentiate into a wide range of mesenchymallineage tissues, mesenchymal stem/stromal cells (MSCs) are under intense investigation for applications in cardiac, renal, neural, joint, and bone repair, as well as in inflammatory conditions and hemopoietic cotransplantation [24]. MSCs are typically harvested from adult bone marrow or fat, but these methods not only require painful invasive procedures, but also are low-frequency sources, with MSCs making up only $0.001 \%$ of bone marrow cells and $0.05 \%$ in fat tissues $[26,27]$.

Traditional fetal MSCs isolation method was described in Guillot's paper [28]. Briefly, first-trimester fetal bone marrow MSCs were obtained by flushing the bone marrow cells out of humeri and femurs using a syringe and a 22-gauge needle. The resultant cells were allowed to adhere to a standard tissue culture flask for 72 hours in MSC medium. Afterwards, they were washed and passaged with Tryple-Select upon confluence, cultured under humidified conditions in $5 \% \mathrm{CO}_{2}$, and routinely cryopreserved in 90\% FCS and 10\% dimethyl sulfoxide (DMSO). Fisk's group had developed a new method to obtain MSCs and this research result would influence deeply a number of patients suffering from serious disease. In their studies, firstly, to develop a feeder cell-free method to produce MSCs from ESCs or iPSCs, they used a widely used commercially available defined medium, mTeSR1(Stem Cell Technologies), which in combination with the cell attachment matrix Matrigel, maintains pluripotency of ESCs/iPSCs without the need for feeder cells or additional basic fibroblast growth factor (bFGF) [29]. Then cells were seeded as large colonies at high confluence, and some cell lines required a one-passage adaptation to mTeSR/Matrigel conditions prior to MSC differentiation. When cells were confluent, the medium was changed to inhibitor differentiation medium including knockout serum replacement (KOSR) medium without bFGF, supplemented with $10 \mu \mathrm{M}$ SB431542(SB) (a kind of transforming growth factor- $\beta$ ) in DMSO. The MSCs could be obtained using this new method in about 10 days, which was more quickly than traditional methods.

In addition to the two new methods developed recently, many researchers had done much work on the isolation and culture technology of stem cells in order to apply it in the treatment of disease more extensively. Fan's group had observed [30] that the embryonic stem cells possessed a relatively loose, open chromatin structure, and the differentiated cells possessed a tight chromatin structure. This research demonstrated for the first time that the state of chromatin compaction was not only the result of cell differentiation, 
but also the cell differentiation needed. Fischbach's group had showed that adipose-derived stem cell could trigger the tumor growth [31]. Yamanaka's group had induced pluripotent stem cells from mouse embryonic [32] and adult human fibroblasts using defined factors [33]. All these studies had promoted the stem cells' application in the treatment of disease including tumor and regenerative medicine.

\section{Molecular Imaging Techniques and Their Application in Stem Cell Research}

Molecular imaging, including bioluminescence imaging (BLI), fluorescence molecular imaging (FMI), positron emission tomography (PET), single photon emission computed tomography (SPECT), and magnetic resonance imaging (MRI) can characterize and quantify biological process at the cellular and molecular level in intact living subjects. It usually exploits specific molecular probes as the source of image contrast to detect the disease and evaluate drug efficacy [34]. In recent years, with the development of molecular imaging including imaging systems and imaging algorithms, molecular imaging has been widely applied in many areas, such as tumor research, drug development, and stem cell research and so on. Take the bioluminescence imaging system as an example, it has been developed from two-dimensional system to three-dimensional systems. Fluorescence imaging system has also been greatly improved in imaging acquisition speed and stability. Meanwhile, many algorithms had been developed to improve the speed and accuracy of image reconstruction, such as Tikhonov regularization method [18], a Born-type approximation BLT method [35], the Bayesian approach [21]. The development in system and algorithm enables molecular imaging to become an important means of stem cell research. Then we will review some researches of molecular imaging on tracking stem cell therapy of cardiovascular and neurological diseases.

\subsection{Molecular Imaging for Tracking Stem Cell Therapy in} Cardiovascular. Cardiovascular disease is the second cause of morbidity and mortality in China, and the leading cause of morbidity and mortality in the United States [38]. One major reason for the high morbidity and mortality is that the heart has an inadequate regenerative response following ischemia caused by myocardial infarction or other chronic cardiovascular diseases $[39,40]$. Novel regenerative therapies like stem cell therapy can promote neovascularization and neomyogenesis, which need to be evaluated using molecular imaging $[41,42]$.

For cardiac stem cell therapy, Bulte's group monitored the trafficking of ${ }^{111} \mathrm{In}$ labeled mesenchymal stem cells after intravenous administration in a porcine myocardial infarction model using SPECT imaging [43]. Cao's group demonstrated the utility of BLI by tracking survival and proliferation of mouse ESCs following cardiac injection in rats in 2006 [44]. Then Li's group made a head-tohead comparison of BLI and MRI using human ESCs in immunodeficient mouse hind limb models and found that MR images showed stable and similar signals in both undifferentiated ESCs and differentiated endothelial cells for 4 weeks, whereas BLI showed divergent survival profiles for the two groups [36]. The result was shown in Figure 1. In addition, Schrepfer's group has used GFP to histologicaly verify the presence of transduced bone marrow mononuclear cells following transplantation into myocardium [45]. All these imaging technologies including BLI, FMI, PET, SPECT, and MRI have been used in tracking stem cell therapy in cardiovascular, which will promote the development of stem cell therapy.

3.2. Molecular Imaging for Stem Cell Therapy in Neurological Diseases. The nervous system is a delicate and complex system, composed of neurons, glial cells, microglia, and cells and blood vessels of the meninges. Human neurological diseases such as Alzheimer's disease, Parkinson's disease, Huntington's disease, spinal cord injury, and multiple sclerosis are caused by loss of different types of neurons and glial cells in the brain and spinal cord [46]. Discovery of the therapeutic potential of stem cells offers new methods for the treatment of neurological diseases. Advances in imaging equipment and technique offer powerful methods for evaluating therapeutic efficacy of neurological diseases $[47,48]$.

For PET imaging, as a common imaging probe, ${ }^{18} \mathrm{~F}-$ FDG has been used to label porcine circulation progenitor cells with the labeling efficiency $91.6 \pm 6.4 \%$ [49]. Furthermore, Kang's group has evaluated the efficacy of stem cell therapy in human heart using PET in clinical studies $[50,51]$. Bjorklund's group has used PET and ${ }^{11} \mathrm{C}$-labeled $2 \beta$-carbomethoxy- $3 \beta$-(4-fluorophenyl) tropane $\left(\left[{ }^{11} \mathrm{C}\right] \mathrm{CFT}\right)$ to obtain parallel evidence of dopaminergic (DA, associated with Parkinson's disease) cell differentiation in vivo [37]. Behavioral recovery of rotational asymmetry at 9 weeks after implantation of ESCs in animal models implicated that ESCs could become a donor source for cell therapy in Parkinson's disease (PD), and the results were shown in Figure 2. Bradbury's group has monitored the long-term viability and proliferation of hESC-derived neural precursor grafts in the brains of immunodeficient and immunocompetent mice using BLI [52]. Their studies demonstrated that there was no significant alteration in the viability of transduced hESCderived neural precursors in immunodeficient models over a 2-month period, but there were variations in proliferative activity among grafted animals. These studies indicate the broad application prospects of molecular imaging techniques in stem cell therapy for nervous disease.

\section{Conclusions and Future Prospects}

As we know, stem cells have the following features. First, self-renewal is the hallmark property of stem cells in normal and diseased tissues. Second, the cells that continue to divide over long periods of time are much more likely to accumulate mutations that cause neoplasia and other diseases. Third, in normal tissues that contain self-renewing stem cells, such as the epithelia, the genetic changes which may cause tumorigenesis probably also occur in the stem cells 


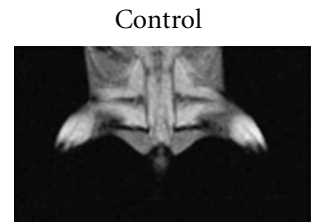

Day 14
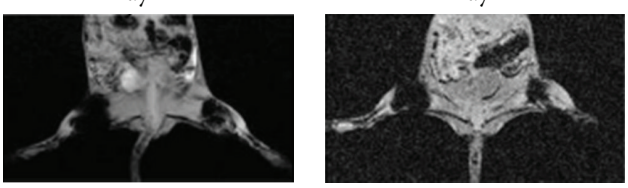

(a)
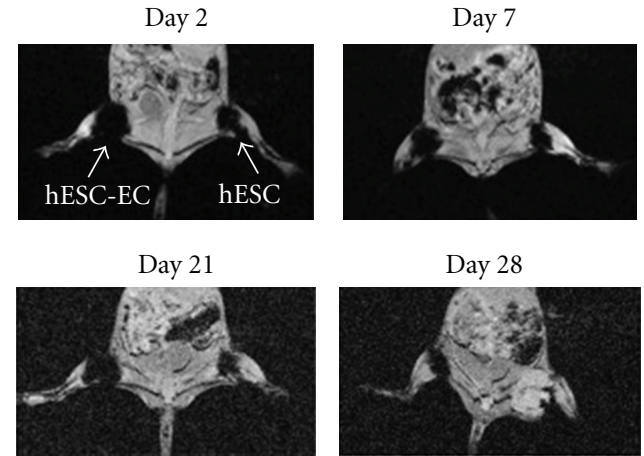

)
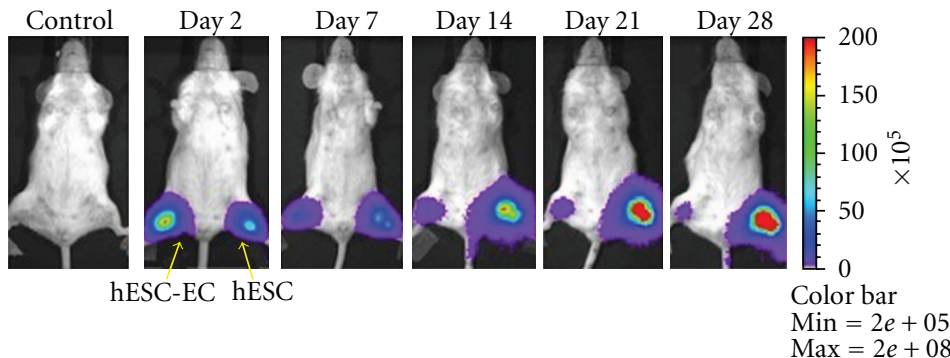

(c)

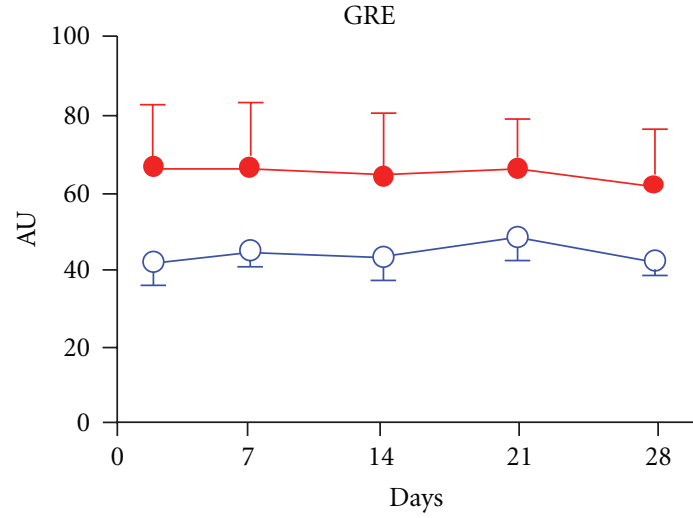

-O- hESC

$\bullet-$ hESC-EC

(b)

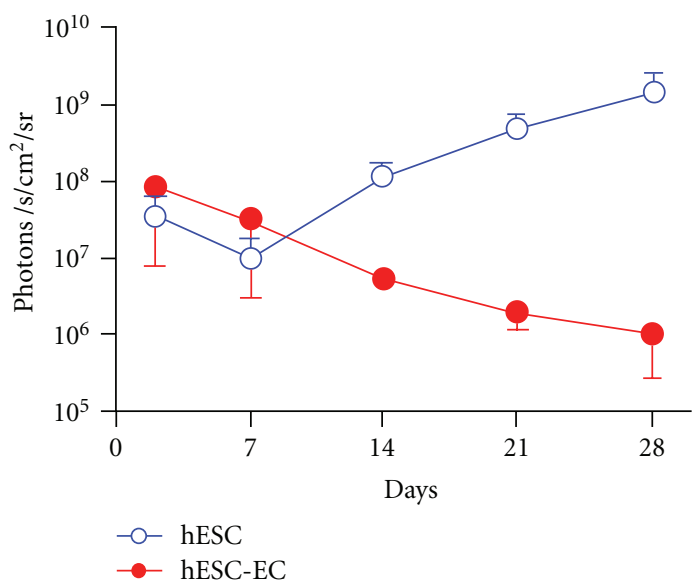

(d)

Figure 1: Direct comparison of reporter gene imaging (genetic labeling) versus iron particle imaging (physical labeling) for tracking stem cells. (a) Human ESCs were cultured under normal conditions or on gelatin/fibronection-coated plates to induce endothelial cell differentiation. These predifferentiated human ESC-derived endothelial cells (hESC-ECs) and undifferentiated ESCs were SPIO-labeled (with Feridex) and $1 \times 106$ cells were then injected into mouse hindlimbs. MR images of one representative animal show the cells at days 2, 7, 14, 21, and 28. (b) MR does not show survival differences between the two groups, as the signal is steady throughout all imaging timepoints, with a higher signal in the hESC-EC group through day 28. (c) These same ESCs were transduced with the human ubiquitin promoter driving fireflyluciferase (Fluc) and enhanced green fluorescence protein (eGFP). These cells were then cultured as in (a) prior to transplantation into the hindlimb of a mouse. (d) BLI showed divergent survival profiles for the two groups, with proliferation of ESC and acute donor cell death of pre-differentiated hESC-ECs. This study demonstrated that MRI provided detailed information on the anatomical location of cells, but not on cell viability. Reporter gene imaging is a better indicator of cell viability and proliferation [36].

or in progeny that acquire the potential for self-renewal [1]. Finally, self-renewing of stem cell is controlled by distinct signaling pathways in different tissues. All the characters of stem cells promote the researches on culture, isolation, clinical application, and other related technologies.

In recent years, many isolation and culture technologies have been proposed, which are reviewed in the above sections. These technologies have promoted the application of the stem cells on research of disease mechanism and clinical therapy. However, most types of stem cells have their own disadvantages for therapeutic applications, such as lack of availability, risk of immune rejection, directional regulation, and ethical controversy. The recent discovery of iPSCs holds the potential to solve these problems. However, the low efficiency of iPSCs generation and their therapeutic safety need to be further studied before initiation of human clinical trials $[53,54]$. The speed and efficiency of iPSCs generation from both mouse and human somatic cells can be enhanced by adding vitamin $\mathrm{C}$ to the culture medium [55] and the safety of iPSCs may be improved by using nonintegrating viral vectors $[56,57]$. Therefore, we expect that clinical application of iPSCs will be achieved in the near future, which will be a historical leap in the medicine area.

To monitor the efficacy of stem cell therapy and develop new isolation and culture technology, it is necessary to improve molecular imaging techniques. For example, new reporter gene systems under development for PET imaging was reported as a new in vivo reporter gene imaging system 


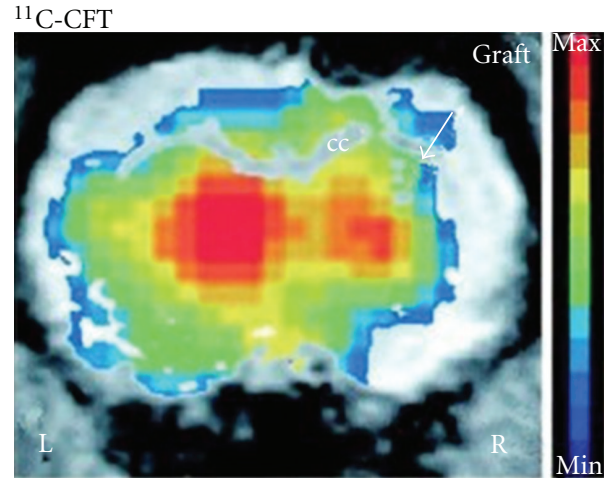

(a)

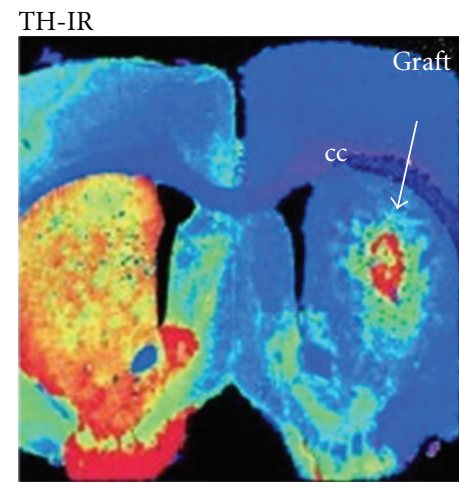

(b)

Figure 2: The specific dopamine transporter (DAT) ligand $\left[{ }^{11} \mathrm{C}\right]$ CFT binding in the right grafted striatum was detected using PET, as shown in this brain slice (a). Increased $\left[{ }^{11} \mathrm{C}\right]$ CFT binding was found in the right striatum, which may correlate with the postmortem presence of TH-immunoreactive (IR) neurons in the graft (b). Color-coded (activity) PET images were overlaid with MRI images for anatomical localization [37].

to monitor transduced ESCs in mice $[58,59]$. Meanwhile, Cerenkov imaging technology is under development for its equivalence with PET $[60,61]$. Optical molecular imaging systems are also being improved from both reconstruction accuracy and speed. Furthermore, "Opti-PET" instrumentation that will combine advantages of optical imaging with high resolution, low cost, and quantitation ability of PET is also under development $[62,63]$. Although none of these imaging technologies fulfill all of the requirements needed for stem cell therapy research at present, their improvement and the development of multimodality molecular imaging system will promote more effectively the understanding of stem cell therapy biology and its mechanisms.

\section{Acknowledgments}

This research is supported by the National Basic Research Program of China (973 Program) under Grant no. 2011CB707700, the Knowledge Innovation Project of the Chinese Academy of Sciences under Grant no. KGCX2YW-907, the National Natural Science Foundation of China under Grant nos. 81071205, 81101095, and 81027002, the Beijing Natural Science Foundation under Grant no. 4111004, the Youth Innovation Promotion Association of CAS, the Fellowship for Young International Scientists of the Chinese Academy of Sciences under Grant no. 2010Y2GA03, and the Chinese Academy of Sciences Visiting Professorship for Senior International Scientists under Grant no. 2010T2G36.

\section{References}

[1] T. Reya, S. J. Morrison, M. F. Clarke, and I. L. Weissman, "Stem cells, cancer, and cancer stem cells,” Nature, vol. 414, no. 6859, pp. 105-111, 2001.

[2] M. Al-Hajj, M. S. Wicha, A. Benito-Hernandez, S. J. Morrison, and M. F. Clarke, "Prospective identification of tumorigenic breast cancer cells," Proceedings of the National Academy of Sciences of the United States of America, vol. 100, no. 7, pp. 3983-3988, 2003.
[3] S. K. Singh, I. D. Clarke, M. Terasaki et al., "Identification of a cancer stem cell in human brain tumors," Cancer Research, vol. 63, no. 18, pp. 5821-5828, 2003.

[4] C. H. Park, D. E. Bergsagel, and E. A. McCulloch, "Mouse myeloma tumor stem cells: a primary cell culture assay," Journal of the National Cancer Institute, vol. 46, no. 2, pp. 411422, 1971.

[5] A. W. Hamburger and S. E. Salmon, "Primary bioassay of human tumor stem cells," Science, vol. 6464, no. 367, pp. 645648, 1994.

[6] R. Pardal, M. F. Clarke, and S. J. Morrison, "Applying the principles of stem-cell biology to cancer," Nature Reviews Cancer, vol. 3, no. 12, pp. 895-902, 2003.

[7] M. Buzzai and J. D. Licht, "New molecular concepts and targets in acute myeloid leukemia," Current Opinion in Hematology, vol. 15, no. 2, pp. 82-87, 2008.

[8] G. G. Wulf, R. Y. Wang, I. Kuehnle et al., "A leukemic stem cell with intrinsic drug efflux capacity in acute myeloid leukemia," Blood, vol. 98, no. 4, pp. 1166-1173, 2001.

[9] A. T. Collins, P. A. Berry, C. Hyde, M. J. Stower, and N. J. Maitland, "Prospective identification of tumorigenic prostate cancer stem cells," Cancer Research, vol. 65, no. 23, pp. 1094610951, 2005.

[10] S. Takaishi, T. Okumura, S. Tu et al., "Identification of gastric cancer stem cells using the cell surface marker CD44," Stem Cells, vol. 27, no. 5, pp. 1006-1020, 2009.

[11] A. Eramo, F. Lotti, G. Sette et al., "Identification and expansion of the tumorigenic lung cancer stem cell population," Cell Death and Differentiation, vol. 15, no. 3, pp. 504-514, 2008.

[12] T. Yamashita, J. Ji, A. Budhu et al., "EpCAM-positive hepatocellular carcinoma cells are tumor-initiating cells with stem/ progenitor cell features," Gastroenterology, vol. 136, no. 3, pp. 1012-e4, 2009.

[13] P. C. Hermann, S. L. Huber, T. Herrler et al., "Distinct populations of cancer stem cells determine tumor growth and metastatic activity in human pancreatic cancer," Cell Stem Cell, vol. 1, no. 3, pp. 313-323, 2007.

[14] E. Lonardo, P. C. Hermann, and C. Heeschen, "Pancreatic cancer stem cells-update and future perspectives," Molecular Oncology, vol. 4, no. 5, pp. 431-442, 2010.

[15] D. A. Harrison and N. Perrimon, "Simple and efficient generation of marked clones in Drosophila," Current Biology, vol. 3, no. 7, pp. 424-433, 1993. 
[16] T. Xie and A. C. Spradling, "decapentaplegic is essential for the maintenance and division of germline stem cells in the Drosophila ovary," Cell, vol. 94, no. 2, pp. 251-260, 1998.

[17] V. Ntziachristos, J. Ripoll, L. V. Wang, and R. Weissleder, "Looking and listening to light: the evolution of whole-body photonic imaging," Nature Biotechnology, vol. 23, no. 3, pp. 313-320, 2005.

[18] Y. Lv, J. Tian, W. Cong et al., "A multilevel adaptive finite element algorithm for bioluminescence tomography," Optics Express, vol. 14, no. 18, pp. 8211-8223, 2006.

[19] C. H. Contag and M. H. Bachmann, "Advances in in vivo bioluminescence imaging of gene expression," Annual Review of Biomedical Engineering, vol. 4, pp. 235-260, 2002.

[20] S. Bhaumik and S. S. Gambhir, "Optical imaging of Renilla luciferase reporter gene expression in living mice," Proceedings of the National Academy of Sciences of the United States of America, vol. 99, no. 1, pp. 377-382, 2002.

[21] J. Feng, K. Jia, C. Qin et al., "Three-dimensional bioluminescence tomography based on bayesian approach," Optics Express, vol. 17, no. 19, pp. 16834-16848, 2009.

[22] K. Liu, J. Tian, Y. Lu et al., "A fast bioluminescent source localization method based on generalized graph cuts with mouse model validations," Optics Express, vol. 18, no. 4, pp. 3732-3745, 2010.

[23] D. A. Fluri, P. D. Tonge, H. Song et al., "Derivation, expansion and differentiation of induced pluripotent stem cells in continuous suspension cultures," Nature Methods, vol. 9, no. 5, pp. 509-516, 2012.

[24] Y. S. Chen, R. A. Pelekanos, R. L. Ellis, R. Horne, E. J. Wolvetang, and N. M. Fisk, "Small molecule mesengenic induction of human induced pluripotent stem cells to generate mesenchymal stem/stromal cells," Stem Cells Translational Medicine, vol. 1, pp. 83-95, 2012.

[25] N. Maherali and K. Hochedlinger, "Guidelines and techniques for the generation of induced pluripotent stem cells," Cell Stem Cell, vol. 3, no. 6, pp. 595-605, 2008.

[26] K. Bieback, S. Kern, A. Kocaömer, K. Ferlik, and P. Bugert, "Comparing mesenchymal stromal cells from different human tissues: bone marrow, adipose tissue and umbilical cord blood," Bio-Medical Materials and Engineering, vol. 18, no. 1, pp. S71-S76, 2008.

[27] S. Kern, H. Eichler, J. Stoeve, H. Klüter, and K. Bieback, "Comparative analysis of mesenchymal stem cells from bone marrow, umbilical cord blood, or adipose tissue," Stem Cells, vol. 24, no. 5, pp. 1294-1301, 2006.

[28] P. V. Guillot, C. Gotherstrom, J. Chan, H. Kurata, and N. M. Fisk, "Human first-trimester fetal MSC express pluripotency markers and grow faster and have longer telomeres than adult MSC," Stem Cells, vol. 25, no. 3, pp. 646-654, 2007.

[29] J. Yu, M. A. Vodyanik, K. Smuga-Otto et al., "Induced pluripotent stem cell lines derived from human somatic cells," Science, vol. 318, no. 5858, pp. 1917-1920, 2007.

[30] Y. Z. Zhang, M. Cooke, S. Panjwani et al., "Histone H1 depletion impairs embryonic stem cell differentiation," PloS Genetics, vol. 8, no. 5, Article ID e1002691, 2012.

[31] E. M. Chandler, B. R. Seo, J. P. Califano et al., "Implanted adipose progenitor cells as physicochemical regulators of breast cancer," Proceedings of the National Academy of Sciences USA, vol. 1, pp. 1-6, 2012.

[32] K. Takahashi and S. Yamanaka, "Induction of pluripotent stem cells from mouse embryonic and adult fibroblast cultures by defined factors," Cell, vol. 126, no. 4, pp. 663-676, 2006.
[33] K. Takahashi, K. Tanabe, M. Ohnuki et al., "Induction of pluripotent stem cells from adult human fibroblasts by defined factors," Cell, vol. 131, no. 5, pp. 861-872, 2007.

[34] T. F. Massoud and S. S. Gambhir, "Molecular imaging in living subjects: seeing fundamental biological processes in a new light," Genes and Development, vol. 17, no. 5, pp. 545-580, 2003.

[35] W. Cong, K. Durairaj, L. V. Wang, and G. Wang, "A Born-type approximation method for bioluminescence tomography," Medical Physics, vol. 33, no. 3, pp. 679-686, 2006.

[36] Z. Li, Y. Suzuki, M. Huang et al., "Comparison of reporter gene and iron particle labeling for tracking fate of human embryonic stem cells and differentiated endothelial cells in living subjects," Stem Cells, vol. 26, no. 4, pp. 864-873, 2008.

[37] L. M. Björklund, R. Sánchez-Pernaute, S. Chung et al., "Embryonic stem cells develop into functional dopaminergic neurons after transplantation in a Parkinson rat model," Proceedings of the National Academy of Sciences of the United States of America, vol. 99, no. 4, pp. 2344-2349, 2002.

[38] D. Lloyd-Jones, "Heart disease and stroke statistics2009update: a report from the American Heart Association Statistics Committee and Stroke Statistics Subcommittee," Circulation, vol. 119, no. 3, pp. 480-486, 2009.

[39] V. F. M. Segers and R. T. Lee, "Stem-cell therapy for cardiac disease," Nature, vol. 451, no. 7181, pp. 937-942, 2008.

[40] T. B. T. Borchardt, "Cardiovascular regeneration in nonmammalian model systems: what are the differences between newts and man?" Thrombosis and Haemostasis, vol. 98, no. 2, pp. 311-318, 2007.

[41] J. C. Wu, M. R. Abraham, and D. L. Kraitchman, "Current perspectives on imaging cardiac stem cell therapy," Journal of Nuclear Medicine, vol. 51, no. 5, pp. 128s-136s, 2010.

[42] M. A. Lijkwan, E. J. Bobs, J. C. Wu, and R. C. Robbins, "Role of molecular imaging in stem cell therapy for myocardial restoration," TCM, vol. 20, no. 6, pp. 183-188, 2010.

[43] B. B. Chin, Y. Nakamoto, J. W. M. Bulte, M. F. Pittenger, R. Wahl, and D. L. Kraitchman, "111 In oxine labelled mesenchymal stem cell SPECT after intravenous administration in myocardial infarction," Nuclear Medicine Communications, vol. 24, no. 11, pp. 1149-1154, 2003.

[44] F. Cao, S. Lin, X. Xie et al., "In vivo visualization of embryonic stem cell survival, proliferation, and migration after cardiac delivery," Circulation, vol. 113, no. 7, pp. 1005-1014, 2006.

[45] K. E. van der Bogt, A. Y. Sheikh, S. Schrepfer et al., "Comparison of different adult stem cell types for treatment of myocardial ischemia," Circulation, vol. 118, no. 14, pp. S121129, 2008.

[46] J. C. Wang, M. Tian, and H. Zhang, "PET molecular imaging in stem cell therapy for neurological diseases," European Journal of Nuclear Medicine and Molecular Imaging, vol. 38, pp. 1926-1938, 2011.

[47] S. U. Kim and J. de Vellis, "Stem cell-based cell therapy in neurological diseases: a review," Journal of Neuroscience Research, vol. 87, no. 10, pp. 2183-2200, 2009.

[48] A. Gera, G. K. Steinberg, and R. Guzman, "In vivo neural stem cell imaging: current modalities and future directions," Regenerative Medicine, vol. 5, no. 1, pp. 73-86, 2010.

[49] B. Doyle, B. J. Kemp, P. Chareonthaitawee et al., "Dynamic tracking during intracoronary injection of18F-FDG- labeled progenitor cell therapy for acute myocardial infarction," Journal of Nuclear Medicine, vol. 48, no. 10, pp. 1708-1714, 2007. 
[50] W. J. Kang, H. J. Kang, H. S. Kim, J. K. Chung, M. C. Lee, and D. S. Lee, "Tissue distribution of 18F-FDG-labeled peripheral hematopoietic stem cells after intracoronary administration in patients with myocardial infarction," Journal of Nuclear Medicine, vol. 47, no. 8, pp. 1295-1301, 2006.

[51] M. Hofmann, K. C. Wollert, G. P. Meyer et al., "Monitoring of bone marrow cell homing into the infarcted human myocardium," Circulation, vol. 111, no. 17, pp. 2198-2202, 2005.

[52] M. S. Bradbury, G. Panagiotakos, B. K. Chan et al., "Optical bioluminescence imaging of human ES cell progeny in the rodent CNS," Journal of Neurochemistry, vol. 102, no. 6, pp. 2029-2039, 2007.

[53] R. P. F. Salewski, E. Eftekharpour, and M. G. Fehlings, "Are induced pluripotent stem cells the future of cell-based regenerative therapies for spinal cord injury?" Journal of Cellular Physiology, vol. 222, no. 3, pp. 515-521, 2010.

[54] R. D. Robbins, N. Prasain, B. F. Maier, M. C. Yoder, and R. G. Mirmira, "Inducible pluripotent stem cells: not quite ready for prime time?" Current Opinion in Organ Transplantation, vol. 15, no. 1, pp. 61-67, 2010.

[55] M. A. Esteban, T. Wang, B. Qin et al., "Vitamin C enhances the generation of mouse and human induced pluripotent stem cells," Cell Stem Cell, vol. 6, no. 1, pp. 71-79, 2010.

[56] M. Stadtfeld, M. Nagaya, J. Utikal, G. Weir, and K. Hochedlinger, "Induced pluripotent stem cells generated without viral integration," Science, vol. 322, no. 5903, pp. 945949, 2008.

[57] W. Zhou and C. R. Freed, "Adenoviral gene delivery can reprogram human fibroblasts to induced pluripotent stem cells," Stem Cells, vol. 27, no. 11, pp. 2667-2674, 2009.

[58] T. Furukawa, T. G. Lohith, S. Takamatsu, T. Mori, T. Tanaka, and Y. Fujibayashi, "Potential of the FES-hERL PET reporter gene system-basic evaluation for gene therapy monitoring," Nuclear Medicine and Biology, vol. 33, no. 1, pp. 145-151, 2006.

[59] S. Takamatsu, T. Furukawa, T. Mori, Y. Yonekura, and Y. Fujibayashi, "Noninvasive imaging of transplanted living functional cells transfected with a reporter estrogen receptor gene," Nuclear Medicine and Biology, vol. 32, no. 8, pp. 821829, 2005.

[60] C. Li, G. S. Mitchell, and S. R. Cherry, "Cerenkov luminescence tomography for small-animal imaging," Optics Letters, vol. 35, no. 7, pp. 1109-1111, 2010.

[61] J. Zhong, J. Tian, X. Yang, and C. Qin, "Whole-body cerenkov luminescence tomography with the finite element SP 3 method," Annals of Biomedical Engineering, vol. 39, no. 6, pp. 1728-1735, 2011.

[62] Y. Zhang, M. Ruel, R. S. B. Beanlands, R. A. deKemp, E. J. Suuronen, and J. N. DaSilva, "Tracking stem cell therapy in the myocardium: applications of positron emission tomography," Current Pharmaceutical Design, vol. 14, no. 36, pp. 3835-3853, 2008.

[63] H. He, M. A. Mortellaro, M. J. P. Leiner, S. T. Young, R. J. Fraatz, and J. K. Tusa, "A fluorescent chemosensor for sodium based on photoinduced electron transfer," Analytical Chemistry, vol. 75, no. 3, pp. 549-555, 2003. 

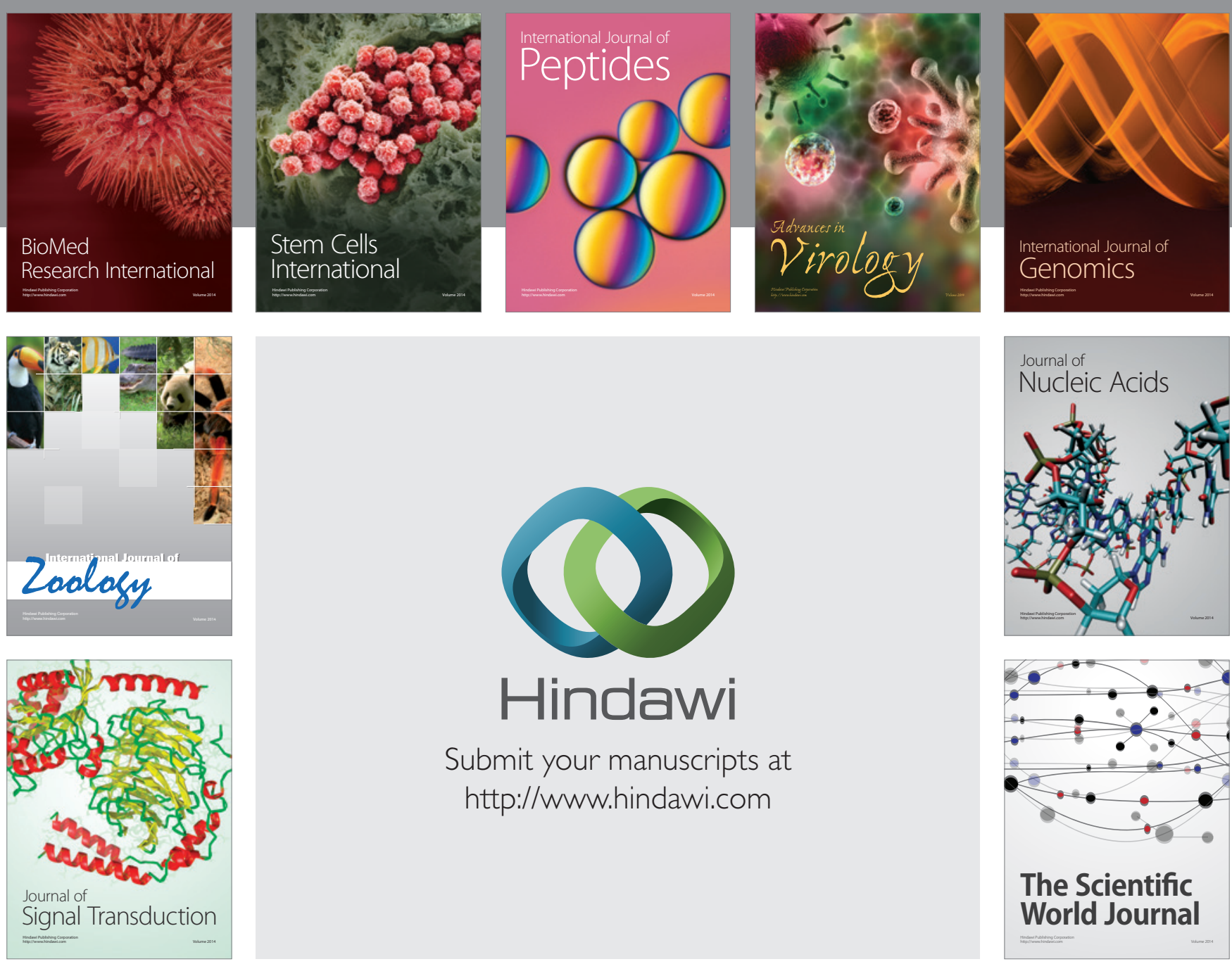

Submit your manuscripts at

http://www.hindawi.com
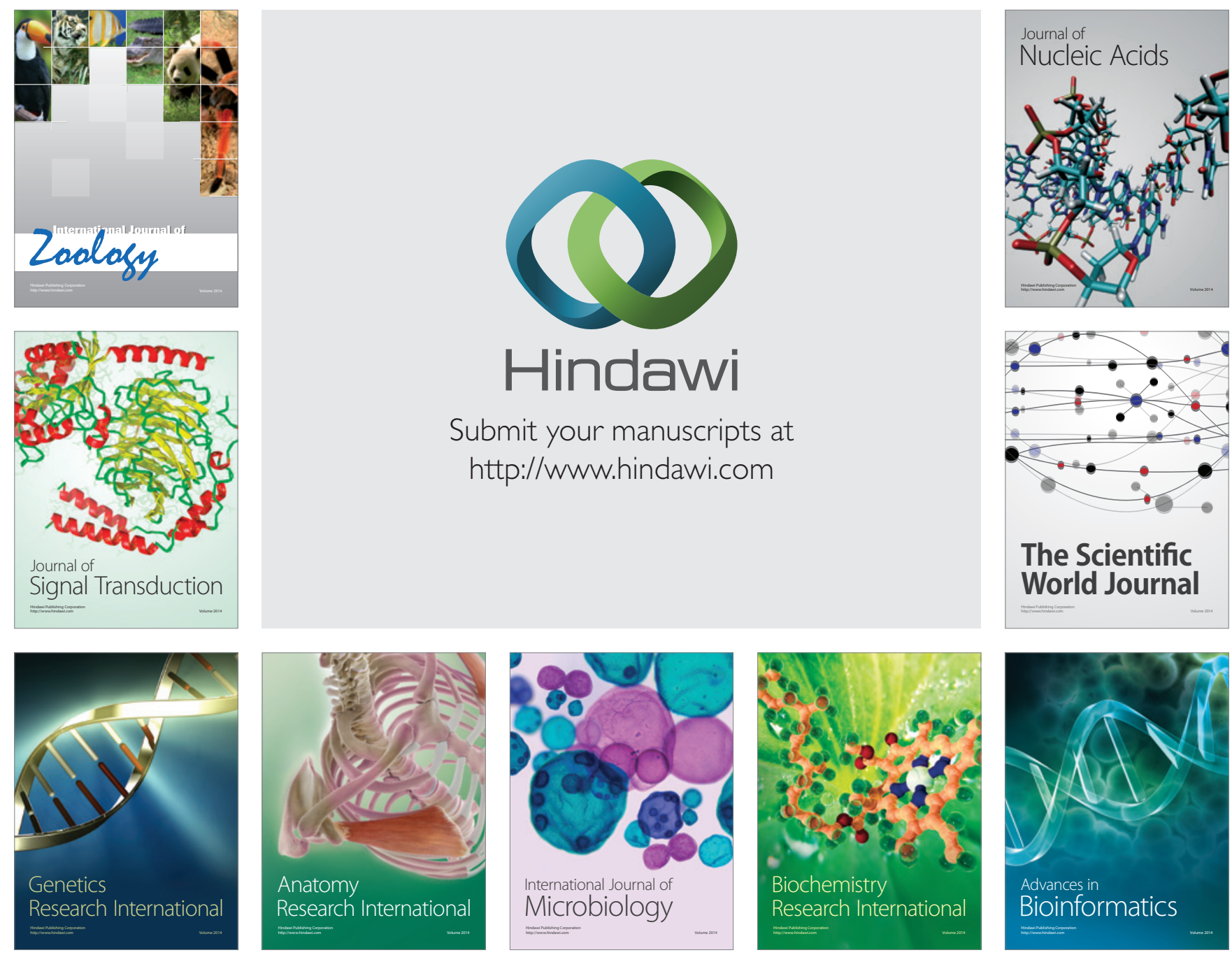

The Scientific World Journal
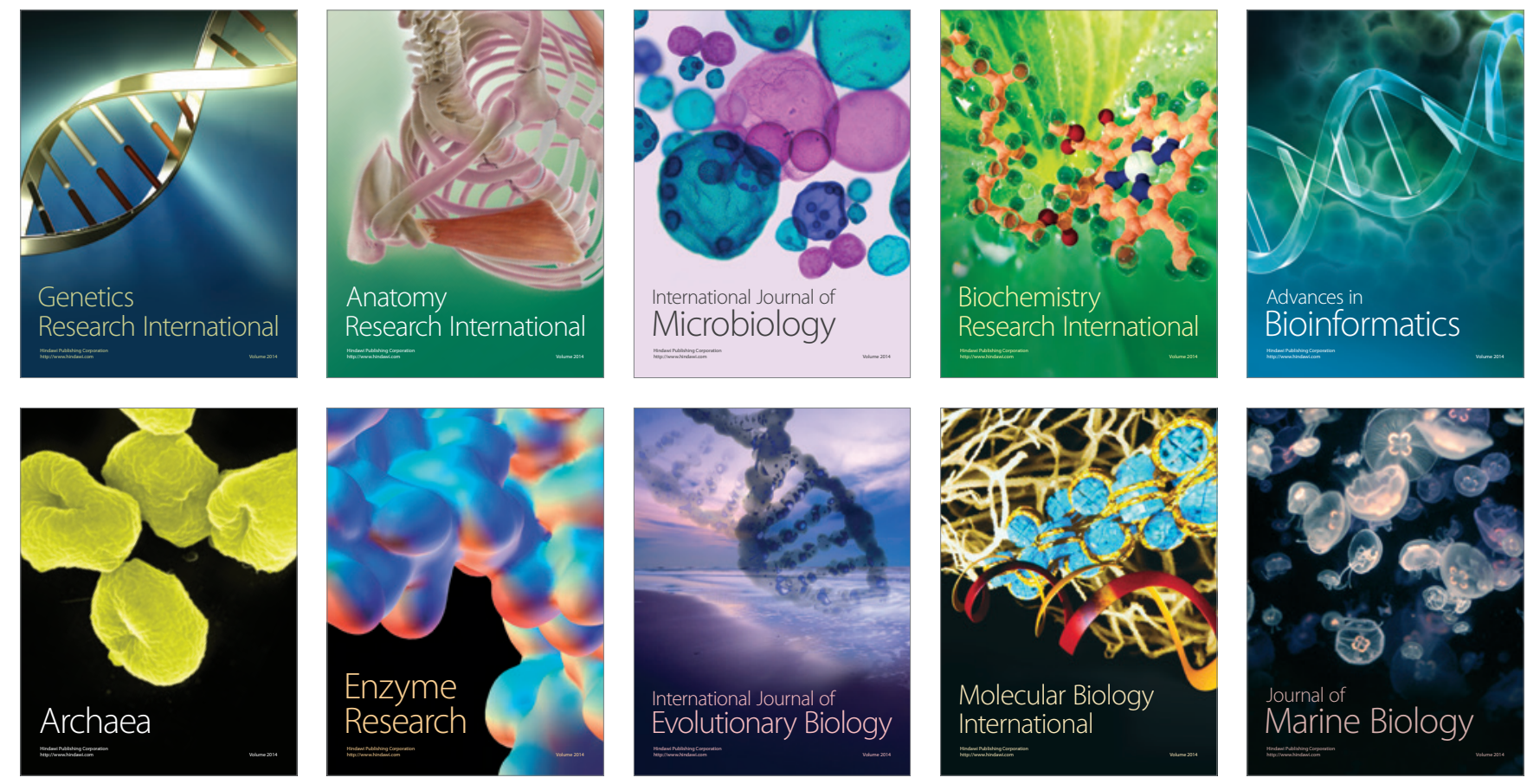